\title{
Sakarya Üniversitesi Diş Hekimliği Fakültesine Ortodontik Şikayet ile Başvuran Hastalarda Tedavi İhtiyacı Farkındalı̆̆ı
}

\author{
Awareness of Treatment Needs among the Patients Applying to Sakarya University's
} Faculty of Dentistry with Orthodontic Complaints

\author{
Refika Topal \\ Sakarya Üniversitesi Diş Hekimliği Fakültesi Ortodonti Anabilim Dalı, Sakarya, Türkiye \\ Yazı̧sma Adresi / Correspondence: \\ Refika Topal \\ Sakarya Üniversitesi Diş Hekimliği Fakültesi Ortodonti Anabilim Dalı \\ Mithatpaşa Mahallesi Adnan Menderes Caddesi No:122/B Adapazarı/ Sakarya, Türkiye \\ T: +905068535992 E-mail : refikatopal@hotmail.com \\ Geliş Tarihi / Received : 22.06.2020 Kabul Tarihi / Accepted : 24.08.2020 \\ Orcid : \\ Refika Topal https://orcid.org/0000-0002-1961-127X \\ ( Sakarya Tip Dergisi / Sakarya Med J 2020, 10(3):415-421) DOI: 10.31832/smj.756459
}

\footnotetext{
$\ddot{0} z$

Amaç Bu çalışmanın amacı, ortodonti kliniğine başvuran hastalarda ortodontik tedavi ihtiyacı farkındalığını tespit etmektir.

Gereçve Çalșma, Sakarya Üniversitesi Diș Hekimliği Fakültesi Ortodonti Anabilim Dalına bașvuran (05.03.2020-17.06.2020), ortodontik tedavi görmemiș 160 hastaya anket Yöntem uygulanarak, Ortodontik Tedavi İhtiyaç İndeksi (IOTN)'nin Estetik Komponent(AC)'i ve Görsel Anolog Skala (VAS) kullanılarak, hastaların ortodontik tedavi ihtiyaç farkındalığı tespit edilmiștir.

Bulgular IOTN-AC İndeks değerinin ve VAS’ñ ortalama değerinin kadınlarda erkeklerden daha yüksek olduğu ve istatistiksel olarak anlamlı olduğu bulunmuștur (p<0.05).

Sonuç Kadınların erkeklerden daha fazla ortodontik tedavi ihtiyacı duydukları, genç erişkin bireylerin de ortodontik tedavi ihtiyaç farkındalığının daha fazla olduğu görülmektedir.

Anahtar Ortodontik Tedavi; Ortodontik İndeks; Estetik Komponent

Kelimeler

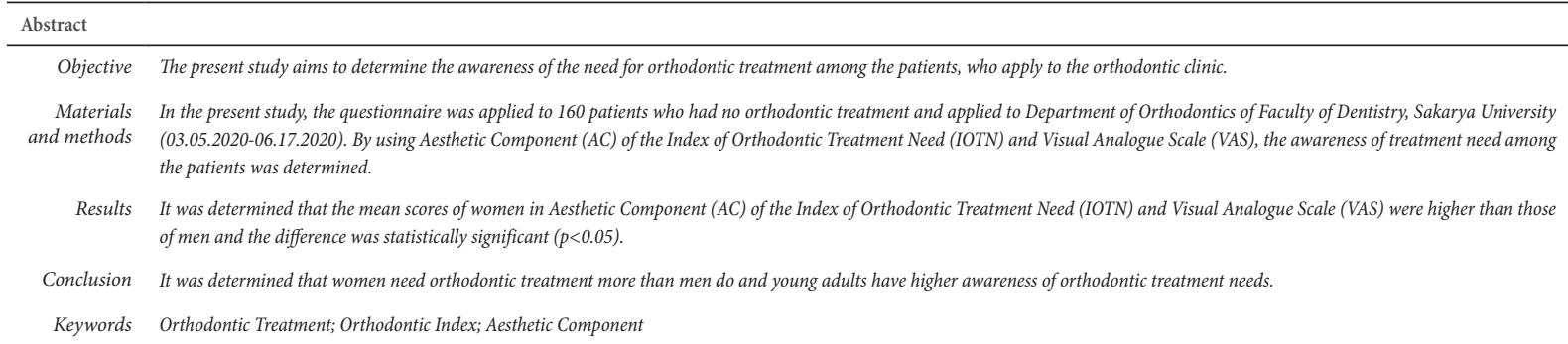




\section{GIIRIŞ}

Dentofasiyal estetik, sosyal etkileşim ve psikolojik refahta önemli rol oynamaktadır. Çünkü insanların kendilerini nasıl algıladıklarını ve toplum tarafından nasıl algılandığını etkilemektedir. ${ }^{1}$ Bireylerde dişsel görünüm ile oluşan kaygıların genellikle ortodontik tedavi olmak istemenin önemli bir nedeni olduğu belirtilmektedir. ${ }^{2}$

Ortodonti hastalarında ortodontik tedavi ihtiyacı alg1larının önemi göz ardı edilemez. Çünkü tedavi gören ve estetik beklenti içerisinde olan ve tedavi sonucunda memnuniyet kazanması gerekenler hastalardır. ${ }^{3} \mathrm{Bu}$ açıdan hastanın algısını anlamak önemlidir. Bireylerin estetik beklentileri ortodontik tedavi seçeneğini ve ortodontik tedavi sonuçlarını etkileyebilmektedir. Bu durumu iyi kavramak, hastanın tedavi için motivasyon seviyesini etkileyebilmektedir. Bireyler kendi ortodontik tedavi ihtiyacı farkındalığı ile tedaviye başlamayıp başkaları tarafından tedaviye ikna edilirse, tedavi süresi boyunca kooperasyon az olabilir ya da hiç olmayabilir. ${ }^{4}$ Ortodontik tedavi ihtiyacının etkin bir şekilde değerlendirilebilmesi için, maloklüzyonlarda estetik bozukluğun göz önünde bulundurulması gereklidir. ${ }^{5}$ Bireyin kendi ortodontik tedavi ihtiyacının farkındalığı, tedavi önceliğini belirlemede anahtar rol oynamaktadır. ${ }^{6}$

Dental estetik algısı oldukça karmaşıktır. Dental estetiğin tanınması ve değerlendirilmesinde farklılıklar olduğu belirtilmektedir. ${ }^{5}$ Çeşitli sosyal, psikolojik ve kişisel faktörler dental görünümde kendini algılama ve ortodontik tedaviye başlama kararını etkilemektedir. ${ }^{7}$ Bunlar cinsiyet, yaş, yaş grubu normları, eğitim düzeyi, sosyal sınıf, kişilik özellikleri, kültür, referans standartları ve değer sistemlerini içermektedir. Ortodontik tedavi ihtiyacı algısı özneldir. Bireylerin maloklüzyonlarının şiddet derecesini abartma veya hafife alma şeklinde görülebilmektedir. Bu nedenle tedavi talebi, aynı maloklüzyon şiddetine sahip bireyler arasında farklılık gösterebilmektedir. ${ }^{8}$

Hastanın ortodontik tedaviye ihtiyaç algısı profesyonel ortodontik tedavi planının önemli bir parçasını oluştur- maktadır. ${ }^{9}$ Birçok çocukta dişlerinin şekli, yüzlerinin görüntüsü estetik algılamalarında önemli rol oynadığı ve psikososyal sağlığa katkıda bulunduğu belirtilmektedir. ${ }^{10,11}$ Bu durum çocuklar ile gençler arasında benlik saygısı ile doğrudan ilişkilendirilmektedir. ${ }^{12,13}$ Daha önceki çalışmalarda çocuklarda ve erişkinlerde dental estetik algısınının ortodontik tedavi ihtiyacı ile ilişkisi değerlendirilmiştir. ${ }^{14-16}$

Maloklüzyonlar diş estetiği algısını etkileyebilse bile, ortodontik tedavi sırasında iş birliği ve motivasyon elde etmek için çocuğun hem diş estetiği hem de ortodontik tedavi ihtiyacı algısını dikkate almak önemlidir. ${ }^{8,17}$

$\mathrm{Bu}$ çalışmada amaç çocuklar, gençler ve erişkin bireylerde Görsel Analog Skala (Visual Analog Scale-VAS) kullanarak ve Ortodontik Tedavi İhtiyacı Endeksi'nin (Index of Orthodontic Treatment Need-IOTN) Estetik Komponent'i (Aesthetic Component- AC) kullanılarak ortodontik tedavi gereksinimi algısını ve dental estetik algısını incelemektir.

\section{GEREÇ ve YÖNTEMLER}

Kesitsel tanımlayıcı tipte planlanan çalışma Sakarya Üniversitesi Diş Hekimliği Ortodonti Anabilim Dalı'na başvuran 13-30 yaşları arasında daha önce ortodontik tedavi görmemiş ve herhangi bir sistemik hastalı̆̆ olmayan 160 (85 kız $(\% 53,1), 75$ erkek $(\% 46,9))$ hastaya anket uygulanarak yürütüldü (05.03.2020-17.06.2020). Hastalara çalışmaya gönüllü katıldıklarını teyit etmek üzere onam formu imzalatıldı ve 160 hastanın tamamı ankete katıldı. Çalışma Sakarya Üniversitesi Girişimsel Olmayan Klinik Araştırmalar Etik Kurulu 04.03.2020 tarihli 71522473/050.01.04/91 sayılı onayı ile yapıldı. Çalışma esnasında Helsinki Deklarasyonu ilkelerine uyularak gerekli hasta onamları alındı.

Anket formu; hastaların cinsiyeti, yaşı, ortodonti kliniğine kimin tarafından yönlendirildiği, dişlerinde ve çenelerindeki şikayetlerinin neler olduğunu araştıran sorulardan oluşturuldu. Daha sonra IOTN' nin AC ölçeğini içeren 10 renkli diş fotoğrafını içeren anket kullanıldı. ${ }^{14,18}$ 
10 fotoğrafta 1. derecedeki resim en iyi dişsel estetiği, 10. Derecedeki resim en kötü dişsel estetiği göstermektedir. ${ }^{19}$ Bu estetik ölçekte bireylerin kendi dişlerine en benzer buldukları diş görünüşünü aynaya bakmadan ve herhangi bir kişi tarafından müdahalede bulunulmadan işaretlemeleri istenildi. Son olarak her bireye kendi dişsel görünümleri hakkındaki algılarını değerlendirmeleri için VAS kullanıld1. VAS daha önce estetik alg1 ve algılanan tedavi ihtiyac1nı değerlendirmek için kullanılmış bir ölçektir. ${ }^{16,20-22}$ VAS herhangi bir yaş grubunda veya herhangi bir sosyokültürel planda olan bireylerle kullanım için uyarlanabilen, bireylerin kendilerini algılama hakkındaki veri elde etmenin ekonomik ve basit bir yöntemi olarak kabul edilmektedir. ${ }^{20,21}$ VAS 100 mm'lik olarak her iki ucunda sözcük tanımlayıcıları bulunan yatay bir çizgidir. $0 \mathrm{~mm}$ sonunda "mümkün olan en kötü diş estetiği” ve 100 mm 'de "mümkün olan en ideal diş estetiği” ifadesi ile sabitlendi. ${ }^{22}$ Bireylerin uygun olduğu yerde ölçeği kesecek şekilde dikey bir çizgi çizerek dişsel görünümlerini değerlendirmeleri istendi.

Verilerin analizi için SPSS Statistics 17.0 paket programında one-way ANOVA, Bonferroni testi, bağımsız örneklemler için Student's t-testi kullanılmıştır. Araştırmadaki verilerin anlamlılık düzeyi $\mathrm{p}<0,05$ olarak belirlenmiştir.

\section{BULGULAR}

Çalışmada, 85 kadın $(\% 53,1)$ ve 75 erkek $(\% 46,9)$ olmak üzere toplam 160 hasta değerlendirilmiştir. Hastaların yaş gruplarına göre sınıflandırılmaları 13-18 yaş 49 kişi (\%30,6), 19-24 yaş 58 kişi (\%36,2), 25-30 yaş 53 kişi $(\% 33,1)$ şeklindedir. Çalışma gurubunun yaş ortalaması $18,05 \pm 0,25$ olarak saptanmıştır. Hasta anket formundaki çoktan seçmeli soruların cevaplarının dağılımı Tablo 1'de gösterilmektedir. 72 bireyin ortodonti kiniğine kendi istekleri ile geldiği, 70 bireyin ise diş hekimi tarafından ortodonti kliniğine yönlendirilmesi ile geldiği görülmektedir. Bireylerde en fazla şikayetin dişlerindeki "yamukluk" ve çapraşıklıktan kaynaklandığı görülmektedir. İkinci sıradaki şikayet sebebinin bireylerin dişlerindeki aralıklardan kaynaklandığı görülmektedir. En az şikayetinse gömük dişlerin varlığının olduğu tespit edilmiştir.

\begin{tabular}{|c|c|c|c|c|c|c|c|c|c|c|c|c|}
\hline & \multicolumn{12}{|c|}{ YÖNLENDİRİLME ŞEKLİ } \\
\hline & \multicolumn{4}{|c|}{ Kendi İsteğiyle } & \multicolumn{4}{|c|}{$\begin{array}{l}\text { Diş Hekimi } \\
\text { Aracilığıyla }\end{array}$} & \multicolumn{4}{|c|}{ Diğer } \\
\hline $\begin{array}{l}\text { HASTANIN } \\
\text { ŞIKAYETİ }\end{array}$ & $\begin{array}{l}\underset{\pi}{\infty} \\
\stackrel{\infty}{-} \\
\stackrel{-}{\sim}\end{array}$ & 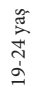 & 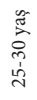 & 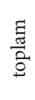 & $\begin{array}{l}\underset{\pi}{2} \\
\stackrel{\infty}{\infty} \\
\stackrel{1}{2}\end{array}$ & 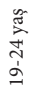 & 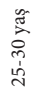 & $\frac{\tilde{E}}{\stackrel{\tilde{J}}{\mathrm{~g}}}$ & 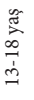 & 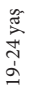 & 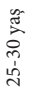 & 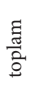 \\
\hline $\begin{array}{l}\text { Dişlerim } \\
\text { "Yamuk"-Çarpık }\end{array}$ & 9 & 15 & 12 & 36 & 5 & 6 & 8 & 19 & 2 & 2 & 3 & 7 \\
\hline Aralıklı Diş & 6 & 9 & 7 & 22 & 4 & 6 & 7 & 17 & 1 & 1 & 1 & 3 \\
\hline $\begin{array}{l}\text { Çenelerim } \\
\text { "yamuk" olması }\end{array}$ & 2 & 5 & 2 & 9 & 9 & 4 & 5 & 18 & 1 & 1 & 1 & 3 \\
\hline Gömük Diş & 1 & 2 & 2 & 5 & 8 & 5 & 3 & 16 & 1 & 2 & 2 & 5 \\
\hline toplam & 18 & 31 & 23 & 72 & 26 & 21 & 23 & 70 & 5 & 6 & 7 & 18 \\
\hline
\end{tabular}

Kadın hastaların erkek hastalara göre AC İndeks ortalama değerlerinin istatistiksel olarak daha yüksek olduğu görülmüştür ( $\mathrm{p}<0.05)$. Aynı zamanda da VAS ortalama değerlerinin de kadınlarda erkeklerden istatistiksel olarak daha yüksek bulunduğu görülmüştür $(\mathrm{p}<0.05)$. Yaş gruplarına göre değerlendirildiğinde ANOVA sonuçlarına göre AC İndeks ortalama değerlerinde üç grup arasında da istatistiksel farklılık olduğu tespit edilmiştir $(\mathrm{p}<0.05)$. VAS ortalama değerleri yaş grupları arasında kıyaslandığında en yüksek ortalamanın 19-24 yaş grubunda olduğu görülmüş ve gruplar arasında istatistiksel olarak anlamlı farklılıklar tespit edilmiştir $(\mathrm{p}<0.05)$ (Tablo 2$)$. 


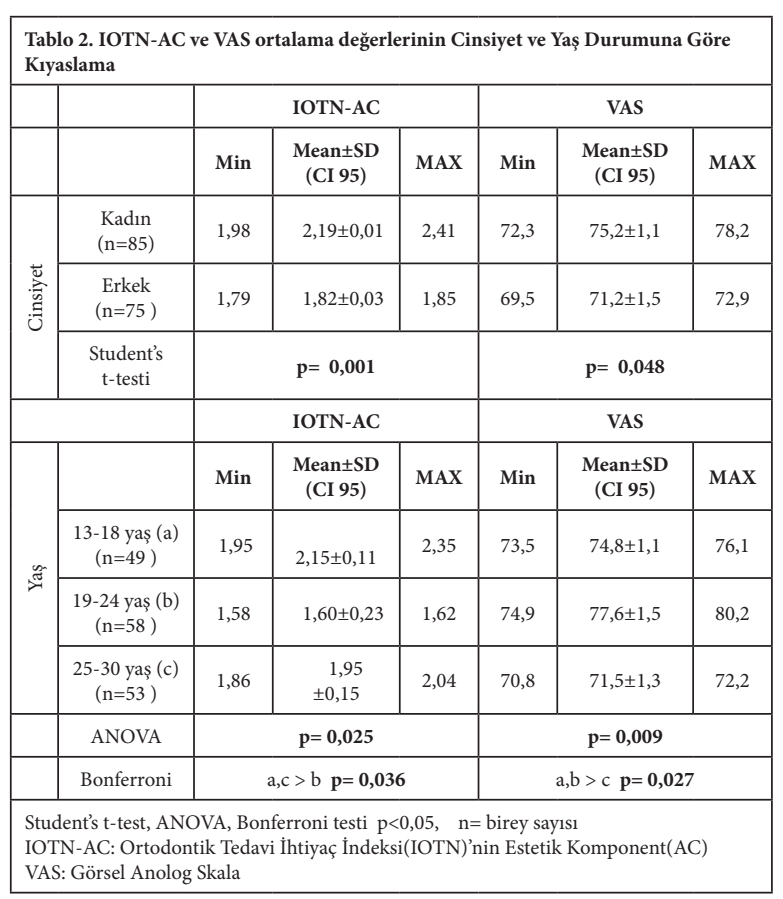

\section{TARTIŞMA}

Bu çalışmada bireylerin ortodontik tedavi ihtiyaç farkındalıklarının tespit edilmesi amaçlanmıştır. Ortodontik tedaviye karar verilirken hastaların öznel tercihleri çok önemlidir. ${ }^{713}$

Böylelikle tedavi planlamasını yaparken bireylerin farkındalıklarından yola çıkarak tedavi planı belirlemede fayda sağlanmaktadır. Çalışmada IOTN'nin AC ölçeğini içeren indeksi ve her bireye kendi dişsel görünümleri hakkındaki algılarını değerlendirmeleri için VAS kullanılmıştır. Ortodontik tedavi ihtiyacı indekslerinin amacı, hastanın kendi algılamasını ve yaşam kalitesi üzerindeki etkisini göz ardı ederek maloklüzyonun oklüzal ve estetik yönlerini değerlendirmektir. ${ }^{23,24}$

Çalışmada bireyler AC İndeks'inde kendi dişlerine en çok benzettikleri fotoğrafı seçmişlerdir. Bireyler ortodontik tedavi ihtiyaç farkındalığında anterior dişlerindeki maloklüzyonları göz önüne almışlardır. Bireylerin mevcut anomalileri ile ortodontik tedaviye ihtiyaç duydukları tespit edilmiştir. Anterior bölgedeki çapraşıklık şikayetinin hastaların en fazla ortodontik tedaviyi tercih etme nedenlerinden olduğu daha önce yapilmış olan çalışmalar tarafindan da belirtilmektedir., ${ }^{4,25,26}$

VAS kullanımı kolay ve pratik uygulanabilen bir skaladır. Çalışmada AC İndeks ile birlikte bireylerde uygulanmıştır. VAS, daha önce yapılan çalışmalarda bireylerin mevcut diş estetik algısını değerlendirmek için kullanılmıştır. ${ }^{20,27}$

Çalışmada bireylerin genellikle dişlerindeki çapraşıklık ve "yamukluk" şikayeti ile ortodonti kliniğine başvurdukları görülmektedir. Maksiller anterior dişler arasında diastema, çapraşıklık, eksik diş varl lğ̆ bireylerin diş estetiğini algllamalarında en olumsuz faktörler olduğu belirtilmiştir. ${ }^{22}$ Aynı zamanda çalışmada, anterior dişlerde aralık bulunması da bireyleri ortodontik tedavi arayışına sevk ettiği görülmektedir. Anterior open bite, deep bite vakaları tedavi edilerek fasiyal görünümde düzeltme sağlanıp bireylerde estetik algının olumlu yönde etkilendiği belirtilmektedir. ${ }^{27}$

VAS, ağrı, yorgunluk veya hastalık gibi öznel deneyimlerin ölçülmesi için yaygın olarak kullanılan bir test tekniğidir. ${ }^{20}$ $\mathrm{Bu}$ test estetik algıyı değerlendirmek için son zamanlarda diğer tıp bilimlerinden ödünç alınmıştır. ${ }^{21,27,28}$ VAS, ekonomik ve basit bir yöntem olup bireyin kendini algılaması hakkında veri elde etmekte kullanılmaktadır. Herhangi bir yaş grubuna veya sosyoekonomik düzey açısından farklı bireylere kolayca uygulanabilmektedir. ${ }^{20}$

Tedavi ihtiyacı farkındalı̆ı̆ında VAS değerlerinin yaş gruplarında farklılık gözlenmiştir. Güzel görünmeyen dişler, bireylerde benlik saygısı üzerinde olumsuz etkiler oluşturabilmektedir. Kendileri ile ilgili olumsuz yargılar oluşturabilmektedir. Bunun sonucunda bireylerde özgüven eksikliği ile birlikte mesleki başarıda olumsuz yönde etkilenebilmektedir. ${ }^{1,26} \mathrm{Bu}$ nedenle ortodontik tedavi için değerlendirme yapılırken hastayı endişelendiren bütün dişsel kaygılar ve estetik bozulmalar göz önünde bulundurulmalıdır. ${ }^{22}$ Yaş arttıkça dişsel estetik algıda bireylerde farkındalığın arttığı yapılan çalışmalarda belirtilmektedir. ${ }^{29} \mathrm{Bu}$ du- 
rumun tersi artan yaş ile birlikte bireylerde tedavi ihtiyacı farkındalığının azaldı $\breve{1}$ da belirtilmektedir. ${ }^{30}$

Çalışmada 19-24 yaş gurubunun AC İndeks ve VAS puanlamasında en fazla ortamala değerleri aldığı görülmektedir. Bu durum bu yaş grubundaki bireylerde ortodontik tedavi ihtiyacının daha fazla farkında olduklarını ve estetik kaygının daha yüksek olduğunu düşündürmektedir. Çalışmalar, çoğu bireyde temelde estetik açıdan iyileşme için ortodontik tedaviye başvurduklarını göstermektedir. ${ }^{8,31}$ Özellikle gençlerin çekici bir diş görünümüne büyük önem verdikleri ve dental estetik problemlerde farkındalıklarının yüksek olduğu görülmektedir. ${ }^{32-35}$

Ergenlik dönemi, dış görünüm ve yüz çekiciliğinin önem verilmeye başladığ farkındalığının artmasına neden olmaktadır. ${ }^{36}$ Bu nedenle, dişsel maloklüzyonların bireyler tarafından kendiliğinden farkedilmesi, bu popülasyondaki bireylerde tedavi planlamasında önemlidir. ${ }^{31}$ Çalışmamızda 13-18 yaş grubundaki bireylerin AC İndeks değeri ortalamasının 2,15 ve VAS' ${ }^{-}$ nın ortlama değerinin 74,8 olduğu ve tedavi ihtiyaçlarının farkında oldukları tespit edilmiştir. Aikins ve Ark'1, 12-18 yaş arasındaki bireylerde ortodontik tedavi ihtiyacı farkındalığını AC skalası ile değerlendirdikleri çalışmalarında $\% 17,5$ oranında bireylerin ortodontik tedavi ihtiyacı olduğunu belirttiklerini tespit etmişlerdir. ${ }^{31}$ Kolawole ve Ark'1, 11-14 yaş grubundaki bireylerde $\% 8$ oranında tedavi ihtiyacı olduğunu belirtmişlerdir. ${ }^{37}$ Ngom ve Ark'1, 12-13 yaş grubundaki bireylerde $\% 13,9$ oranında tedavi ihtiyacı farkındalığının olduğunu belirtmişlerdir. ${ }^{38}$ Etnik köken, farklı yüz görünümleri bireyler tarafından beğenilen oklüzyon ve dişsel estetik algılarında farklılıklar oluşturmaktadır. Dolayısıyla tedavi ihtiyacı farkındalığında ve tedavi beklentileri arasında farklılıklar gözlendiği belirtilmektedir. ${ }^{31}$

Çalışmada kadınların erkeklere oranla AC İndeks değerinin ve VAS’ın ortalama değerlerinin daha yüksek oranda olduğu tespit edilmiştir. Bu da tedavi gereksiniminin daha fazla farkında olduklarını düşündürmektedir. Yapılan ça- lışmalarda bireylerde farklı yaş grupları arasında ve cinsiyetler arasında ortodontik tedavi ihtiyaç farkındalığında gruplar arasında anlamlı farklılık olmadığı belirtilmektedir. ${ }^{15,31}$ Aikins ve Ark'1, yaş ve cinsiyetler arası ortodontik tedavi ihtiyaç farkındalığının anlamlı bulunmamasını bireylerin maloklüzyon varlığına dair farkındalık eksikliğinden kaynakladığını belirtmektedir. ${ }^{31}$ Abu Alhajia ve Ark'ı, 13 ve 17 yaşlarındaki kız bireylerin, 13 ve 17 yaşındaki erkeklerde göre daha fazla ortodontik tedavi ihtiyacı farkında olduklarını belirtmektedir. ${ }^{39}$

Diğer çalışmalar da ise kızların erkeklere göre AC İndeks değerlerinde daha fazla ortodontik tedavi ihtiyacı olduğu belirtilirken, erkeklerin kızlara göre daha fazla ortodontik tedavi ihtiyacının olduğunu belirtilen çalışmalar da bulunmaktadır. ${ }^{40-42}$ Öte yandan AC İndeksi’nin kullanıldığ 1 ve cinsiyetler arası tedavi ihtiyacında farkındalıklarında farklılı̆̆ın olmadığını belirten çalışmalar da mevcuttur. ${ }^{43-45}$

Çalışmada bireylerin ortodonti kliniğine en çok kendi isteğiyle başvuruda bulunduğu görülmektedir. Kendi isteği ile başvuranların en çok 19-24 yaş grubundaki bireyler olduğu görülmektedir. İkinci sırada bireylerin ortodonti kliniğine diş hekimi yönlendirmesiyle geldiği görülmektedir. Erdinç ve Erol, ortodonti kiniğine başvuran hastaların en fazla kendi isteğiyle geldiklerini ve ikinci olarak da diş hekimi yönlendirmesiyle geldiklerini belirtmişleridir. ${ }^{46}$ Kendi isteğiyle ortodonti kliniğine gelen bireylerin çoğunluğunun lise eğitimi görmekte olan bireylerden oluştuğunu belirtmektedirler.

Çalışmada bireylerin en fazla ön dişlerindeki "yamukluk" ve çapraşıklık şikayeti ile ortodonti kliniğine başvurdukları görülmektedir. Klages ve Ark’', bireylerin arasında cinsiyet ayrımı yapmadan en fazla ön dişlerindeki görüntüsünden memnuniyetsizliğini belirtilmektedir. ${ }^{47}$ Çalışmada bireylerin ortodontik şikayet sebebinde ikinci sırada anterior dişlerde aralık bulunmasıdır. Anterior bölgedeki dişlerde ortodontik düzensizliğin en çok şikayet edilen unsur olduğunu belirten çalışmalar ile benzer sonuçlar mevcuttur. ${ }^{26,48}$ 
Önümüzdeki zamanda daha fazla katılımcı sağlanarak, ortodontik tedavi ihtiyacını belirleyici sorunların daha geniş kapsamlı hazırlanıp, bireylerde ortodontik tedavi ihtiyacı farkındalığının tespiti sağlanabilir. Böylece bireyler kliniğe geldiklerinde ortodontik tedavide öncelik tercihini ve tedavi planlamasında bireylerin düşünceleri göz önüne alınarak hastaların tedavi kooperasyonunda olumlu yönde etki edeceği düşünülmektedir.

\section{SONUÇ}

Ortodontik tedavi ihtiyacının bireysel farkındalığında kadınların erkeklerden daha fazla ortodontik tedavi ihtiyacı duydukları, genç erişkin bireylerin de ortodontik tedavi ihtiyaç farkındalığının daha fazla olduğu görülmektedir. Bütün bunların ışı̆̆ında bireylerin kendi estetik algılarının farkındalığı ve tedavi planlamasında fikirlerine öncelik verilmesi hekimlerin ve hastaların tedavide iş birliği içerisinde yol almalarının hasta memnuniyetini arttıracağı ve tedavi başarısını olumlu yönde etkileyeceği düşünülmektedir.

Çalışma Sakarya Üniversitesi Girişimsel Olmayan Klinik Araştırmalar Etik Kurulu 04.03.2020 tarihli $71522473 / 050.01 .04 / 91$ sayılı onayı ile yapıldı. 


\section{Sakarya Tip Dergisi 2020;10(3):415-421}

TOPAL, Ortodonti Hastalarında Farkındalık

\section{Kaynaklar}

1. Marques LS, Ramos-Jorge ML, Paiva SM, Pordeus IA. Malocclusion: esthetic impact and quality of life among Brazilian school children. Am J Orthod Dentofacial Orthop 2006;129 (3): 424-427.

2. Reichmuth M, Greene KA, Orsini MG, Cisneros GJ, King GJ, Kiyak HA. Occlusal perceptions of children seeking orthodontic treatment: impact of ethnicity and socioeconomic status. Am J Orthod Dentofacial Orthop 2005; 128(5):575- 582.

3. She-Te Yeh M, Koocheck AR, Vlaskalic V, Boyd R, Richmond S. The relationship of 2 professional occlusal indexes with patient's perception of aesthetics, function, speech and orthodontic treatment need. Am J Dentofacial Orthop 2000: 118(4): 421-428.

4. Gosney MB. An Investigation into some of the factors influencing the desire for orthodontic treatment. Br J Orthod 1986; 13(2): 87-94.

5. Borzabadi-Farahani A, Borzabadi-Farahani A, Eslamipour F. Orthodontic treatment needs in an urban Iranian children, an epidemiological study of 11-14 year old children. Eur J Paediatr Dent 2009; 10(2): 69- 74.

6. Miguel JA; Sales HX, Quintao CC, Oliveira BH, Feu D. Factors associated with orthodontic treatment seeking by 12-15 year old children at a state university funded clinic. J Orthod 2010; 37(2):100-106.

7. Marques LS, Pordues IA, Ramos- Jorge ML, Filogonio CA, Filogonio CB, Pereira LJ, et al. Factors associated with desire for orthodontic treatment among Brazilian adolescents and their parents. BMC oral Health 2009;9: 34-40.

8. Shaw WC. Factors influencing the desire for orthodontic teatment. Eur J Orthod 1981; 3(3): 151-162.

9. Stenvik A, Espeland L, Mathisen A. A longitudinal study on subjective and objective orthodontic treatment need. Eur J Orthod 1997;19 (1):85-92.

10. Izabela $G$. The value of the aesthetic component of the Index of Orthodontic Treatment Need in the assessment of subjective orthodontic treatment need. Eur J Orthod 2003;25(1):57-63.

11. Birkeland K, Bøe OE, Wisth P. Relationship between occlusion and satisfaction with dental appearance in orthodontically treated and untreated groups. Eur J Orthod 2000;22(5):508518 .

12. Phillips C, Edwards Beal KN. Self-concept and the perception of facial appearance in children and adolescents seeking orthodontic treatment. Angle Orthod 2009;79 (1): 12-16.

13. Mandall NA, Wright J, Conboy FM, et al. The relationship between normative orthodontic treatments need and measures of consumer perception. Community Dent Health 2001; 18:3-6.

14. Brook PH, Shaw WC. The development of an index of orthodontic treatment priority. Eur J Orthod 1989: 11(3): 309-20

15. Mandall NA, MacCord JF, Blinkhorn AS, Worthington HV, O'Brien KD. Perceived aesthetic impact of malocclusion and oral self perception in 14-15 year ols Asaian and Caucasian children in greater Manchester. Eur J Orthod 2000; 22(2):175-183.

16. Kolawole KA, Ayeni OO, Osiatuma VI. Evalauation of self-percevied dental aesthetics and orthodontic treatment need among young adults. Arch Oral Res 2012; 8(2): 111-119.

17. Daniel A, Seacat J, Inglehart M. Orthodontic treatment motivation and cooperation. A cross-sectional analysis of adolescent patients' and parents' responses. Am J Orthod Dentofacial Orthop 2009;136 (6):780-787.

18. Evans $R$, Shaw W. Preliminary evaluation of an illustrated scale for rating dental attractiveness. Eur J Orthod 1987;9 (1):314-318.

19. Salih NF, Lindsten R, Bagesund M. Perception of orthodontic treatment need among Swedish children, adolescents and young adults. Acta Odontologica Scandinavia 2017; 75(6): 407-412

20. Bernabe E, Kresevic VD, Cabrejos SC, Flores-Mir F, Flores-Mir C. Dental Aesthetic self perception in young adults with and without previous orthodontic treatment. Angle Orthod 2006; 76(3): 412-416.

21. Hamdan AM. The relationship between patient, parent and clinician perceived need and normative orthodontic treatment need. Eur J Orthod 2004; 26(3): 265-271.

22. Bernabe E, Flores-Mir C. Influence of Anterior Occlusal Characteristic on Self-perceived Dental Appearence in Young Adults. Angle Orthod 2007; 77(5): 831-836.

23. Onyeaso CO, Aderinokun GA. The relationship between Dental Aesthetic Index (DAI) and perceptions of aesthetics, function and speech amongst secondary school children in Ibadan, Nigeria. Int J Paediatr Dent 2003; 13: 336-341.

24. de Oliveira CM, Sheiham A, Tsakos G, O'Brien KD. Oral health related quality of life and the IOTN index as predictors of children's perceived needs and acceptance for orthodontic treatment. Br Dent J 2008; 204:1-5.
25. Tuominen ML, Tuominen RJ. Factors associated with subjective need for orthodontic treatment among Finnish university applicants. Acta Odontol Scand 1994;52(2):106-110.

26. Espeland LV, Stenvik A. Perception of personal dental appearance in young adults: relationship between occlusion, awareness, and satisfaction. Am J Orthod Dentofacial Orthop 1991;100(3):234-241

27. Flores-Mir C, Silva E, Barriga MI, Lagrave 're MO, MajorPW. Lay person's perception of smile aesthetics in dental and facial views. J Orthod 2004;31 (3):204-209.

28. Howells DJ, Shaw WC. The validity and reliability of ratings of dental and facial attractiveness for epidemiologic use. Am J Orthod 1985; 88 (5): 402-408.

29. Cooper S, Mandall NA, DiBiase D, Shaw WC. The reliability of the Index ofOrthodontic Treatment Need over time J Orthod 2000; 27(1): 47-53.

30. Tuominen ML, Nyström M, Tuominen RJ. Subjective and objective orthodontic treatment need among orthodontically treated and untreated Finnsih adolescents. Community Dent Oral Epidemiol 1995; 23(5): 286-290.

31. Aikins EA, Costa OO, Onyeaso CO, Isiekwe MC. Self-Perception of Malocclusion Among Nigerian Adolescentes Using The Aesthetic Component of The IOTN. The Open Dentistry Journal 2012; 6: 61-66.

32. Flores-Mir C, Major PW, Salazar FR. Self-perceived orthodontic treatment need evaluated through 3 scales in a university population. J Orthod 2004; 31:329-334.

33. Helm S, Petersen PE, Kreiborg S, Solow B. Effect of separate malocclusion traits on concern for dental appearance. Commun Dent Oral Epidemiol 1986; 14 (4): 217-220.

34. Baldwin DC. Appearance and aesthetics in oral health. Commun Dent Oral Epidemiol 1980: 8(5): 244-256.

35. Tulloch JFC, Shaw WC, Smith A. A comparison of attitudes towards orthodontic treatment in British and American communities. Am J Orthod 1984; 85(3): 253-259.

36. Mugonzibwa EA, Kuijpers-Jagtman AM, Van't Hof MA, Kikwilu EN. Perceptions of dental attractiveness and orthodontic treatment need among Tanzanian children. Am J Orthod Dentofacial Orthop 2004; 125(4): 426- 434.

37. Kolawole KA, Otuyemi OD, Jeboda SO, Umweni AA. Awarenessof malocclusion and desire for orthodontic treatment in 11-14 Year Old Nigerian schoolchildren and their parents. Aust Orthod J 2008;24: 21-25.

38. Ngom PI, Diagne F, Dieye F, Diop-Ba K, Thiam F. Orthodontic treatment need and demand in Senegalese school children aged 12- 13 years. Angle Orthod 2007; (77)2: 323-330.

39. Abu Alhajia ESJ, Al-Nimri KS, Al-Khateeb SN. Self-perception of malocclusion among Jordanian schoolchildren. Eur J Orthod 2005; 27 (3): 292-295.

40. Nguyen SM, Nguyen MK, Saag M, Jagomagi T. The need for orthodontic treatment among Vietnamese School Children and young adults. Int J Dent 2014: 1-5.

41. Fariba S, Sirous R. Use of the index of orthodontic treatment need in a school population of Zahedan. Life Sci J 2013; 10(2): 240-244.

42. Khanal L, Giri J, Gaire H. Epidemiology of Malocclusion and Assessment of Orthodontic Treatment Needs Among BDS Students of BPKIHS, Dharan, Nepal. Webmed Central Dentistry 2012; 3(7): 1-18.

43. Ucuncu N, Ertugay E. The use of the index of orthodontic treatment need (IOTN) in a school population and referred population. J Orthod 2001;28(1):45-52.

44. Alatrach $A B$, Saleh FK, Osman E. The prevalence of malocclusion and orthodontic treatment need in a sample of Syrian chlldren. ESJ 2014; 10(30): 230-247.

45. Puertes-Fernández N, Montiel-Company JM, Almerich-Silla JM, Manzanera D. Orthodontic treatment need in a 12-year-old population in the Western Sahara. Eur J Orthod 2011; 33(4): 377-380.

46. Erdinç EA, Erol A. Ortodontik Tedaviye Başvuran 13-20 Yaş Grubu Hastaların Ortodontik Düzensizliklerini Algılayışlarının ve Tedavi ile İlgili Beklentilerinin Değerlendirilmesi. EÜ Dişhek Fak Derg 2009; 30:21-27.

47. Klages $U$, Claus $N$, Wehrbein $H$, Zentner A. Development of a questionnaire for assessment of the psychosocial impact of dental aesthetics in young adults. Eur J Orthod 2006; 28(2): 103-111.

48. Ingervall B, Hedegard B. Awareness of malocclusion and desire of orthodontic treatment in 18-year old Swedish men. Acta Odontol Scand 1974; 32:93-101. 